\title{
Guest Editor Introduction
}

Professor Douglas J. Mathisen is an internationally renowned attending cardiothoracic surgeon based at the Massachusetts General Hospital in Boston in the United States of America. As the Chief of the Division of Thoracic Surgery as well as the Program Director for Cardiothoracic Surgery, Professor Mathisen's clinical and research contributions have helped make significant strides forward in the realm of cardiothoracic surgery.

Professor Mathisen's medical journey started when he completed medical studies at the University of Illinois, College of Medicine in 1974. He was general surgery resident and cardiothoracic resident at the Massachusetts General Hospital from 1974 to 1982. He then spent two years in the Surgery Branch of the National Cancer Institute of Health, Bethesda, Maryland. Subsequently, he joined Massachusetts General's Thoracic Surgery unit in 1984.

Professor Mathieson's career embodies selfless service and commitment to leadership in the field of cardiothoracic surgery. This is seen through his roles as past President of the Thoracic Surgery Directors Association, past Director of the American Board of Thoracic Surgery, past Chairman of the Residency Review Committee, past Treasurer, past President of the Society of Thoracic Surgeons and past Councillor of the European Association of Cardiothoracic Surgery. He has published over 380 articles and book chapters and written five books.

At the Massachusetts General Hospital, he has been Chief of Thoracic Surgery since 1994, Chief of Cardiac Surgery 20072011, and Program Director in Cardiothoracic Surgery since 1995. He was a previous member of the Physicians Organization Executive Committee, Board of Directors and General Executive Committee. For his lifetime service and contributions to this field, Professor Mathisen received the Distinguished Service Award from the Society of Thoracic Surgeons at the 2014 Annual Meeting.

We appreciate the opportunity to have Professor Mathisen inspire us with his contribution of a wealth of knowledge and experience to this current issue of the Annals of Cardiothoracic Surgery.

Kevin Phan
(Email: kphan.vc@gmail.com)

Tristan D. Yan

(Email: tristanyan@annalscts.com)

doi: $10.21037 /$ acs.2018.03.11

Conflicts of Interest: The authors have no conflicts of interest to declare.

View this article at: http://dx.doi.org/10.21037/acs.2018.03.11 